\title{
Activity and Stability of the Alcohol Biosensor Using Acetobacter aceti Biofilm on Screen-Printed Carbon Electrode
}

\author{
Dyah Iswantini ${ }^{*}$, Fitriani Indahsari ${ }^{1}$, Akhiruddin Maddu$^{2}$, Novik Nurhidayat ${ }^{3}$, Henny Purwaningsih ${ }^{1}$, Sri Sugiarti ${ }^{1}$ \\ ${ }^{1}$ Department of Chemistry, Bogor Agricultural University, Bogor, Indonesia \\ ${ }^{2}$ Department of Physics, Bogor Agricultural University, Bogor, Indonesia \\ ${ }^{3}$ Division of Microbiology-RC for Biology, Indonesian institute of Sciences, Cibinong, Indonesia
}

\section{ARTICLE INFO}

Article history:

Received January 11, 2019

Received in revised form March 21, 2019

Accepted September 9, 2019

\section{KEYWORDS:}

biofilm,

A. aceti,

ethanol biosensor

SPCE,

alcohol oxidase,

halal

\begin{abstract}
Most of the alcohol analytical methods are robust and instrumentally expensive. An alternative of ethanol biosensor based on selected biofilm forming Acetobacter aceti bacteria producing alcohol oxidase was constructed on a screen-printed carbon electrode. The enzyme specifically oxidizes the ethanol and generate electrical current that then electrochemically detected and measured by cyclic voltammetry method. A scanning electron microscopic analysis indicated that the biofilm was formed firmly in the electrode. This constructed biosensor reached its optimum at biofilm formed by bacteria of $1.33 \times 10^{10}$ cells $/ \mathrm{ml}$, temperature of $27^{\circ} \mathrm{C}$, and pH 7. The enzyme kinetic had KM and $V \max A O X$ values of $3.5 \mathrm{~mm}$ and 125 $\mu \mathrm{A}$ respectively. The biosensor had detection and quantization limit of 0.003 and $0.009 \%$, respectively, and a sensitivity of $57.29 \mu \mathrm{A}(\%)^{-1}$. A linearity and relative deviation value were revealed at 0.993 and $1.95 \%$ respectively. The biosensor was relatively specific and had no interferences with methanol, sodium chloride and citric acid as the common interferences of ethanol compounds. Furthermore, the biosensor had been stably for at least 55 days. Therefore, this constructed biosensor should be developed into a prototype for a practical effective analysis.
\end{abstract}

\section{Introduction}

Alcohol in the form of ethanol or ethyl alcoholis widely found and used foods and beverages. The Indonesian Ulama Council (MUI) through it decree No. 4/2003 limits the alcohol in the food and beverage products is to $1 \%$. The alcohol use as a stabilizer or food and drink coloring is limited to $0.5 \%$. The foods and beverages contain alcohol beyond these limitsare categorized as haram. Alcohol itself could be a toxic compound (Niculecsu et al. 2002) and serve as the third largest risk factor of disease and disability in the world (Santos et al. 2003). According to (Rotariu et al. 2004) high alcohol consumption can affect nervous system, circulatory system, and digestive system. Several methods have been developed for the determination of ethanol content such as HPLC (Yarita et al. 2002), GC/MS (Apers et al. 2003), FT-Raman spectrometry (Mendes et al. 2003), photometry, colorimetry (Zanon et al. 2007). These methods require a relatively a longtime analysis,

\footnotetext{
* Corresponding Author

E-mail Address: dyahis@apps.ipb.ac.id

complicated sample preparation process, expensive instrumentation, and need a trained operator (Azevedo et al. 2005). Therefore, a new biosensorbased electrochemical method has been developed to detect ethanol (Shkotova et al. 2005; Carelli et al. 2006; Türkarslana et al. 2010; Rama et al. 2012; Cinti et al. 2017). The biosensors has several advantages such as faster, simple, inexpensive, sensitive, selective techniques, and can be miniaturized (Alferov et al. 2011). As such, alcohol biosensors based on alcohol oxidase (Rama et al. 2012; Kurbanoglu and Toppare 2014; Chinnadayyala et al. 2015) and alcohol dehydrogenase (Bilgi and Ayranci 2016; Alpat and Telefoncu 2010) have been developed. Unfortunately their uses in biosensor construction are still limited by the tedious, time-consuming and costly enzyme purification procedures. In addition, multiple enzymes or cofactor/coenzyme are often required to generate measurable products (Wen et al. 2013).

In this research, a selected biofilm forming Acetobacter aceti bacteria producing alcohol oxidase (AOX) was inoculated to form biofilm on a screenprinted carbon electrode (SPCE). The bacterial biofilm and its enzyme are more practically produced and manipulated than that of its pure enzyme 
immobilization (Su et al. 2010). The biofilm itself is relatively stable and resistant to environmental condition (Abed et al. 2012; Pantanella et al. 2013). The most important component in a biosensor is the electrode. The previous simple Carbon-based electrode has shown to be slow in collecting ions around its surface and a less stable response resulting in poor sensitivity, stability, and repetition (Xia et al. 2010). The objective of this study was to improve the activity and stability of ethanol biosensors by forming biofilm $A$. aceti producing alcohol oxidase on the surface of screen-printed carbon electrode.

\section{Materials and Methods}

\subsection{Acetobacter aceti's Biofilm Preparation}

The selected pure colony $A$. aceti K5 was grown on Acetobacter aceti selective liquid medium at $30^{\circ} \mathrm{C}$ with a shaker speed of $90 \mathrm{rpm}$ for 20 hours to reach cell density of $\mathrm{OD}_{600}: 1,600$. The bacterial cells were harvested by $10,000 \mathrm{rpm}$ centrifugation at $4^{\circ} \mathrm{C}$ for 5 minutes. The cell pellet was wash twice and then resuspended in $50 \mathrm{~mm}$ phosphate buffer of $\mathrm{pH}$ 7. The biofilm forming assay was carried out in a microtiter plate and crystal violet staining (Merritt et al. 2011). The selected biofilm forming bacteria was dropped in $100 \mu \mathrm{l}$ suspension onto the SPCE and allowed to form biofilm for 3 days. The biofilm was then observed under scanning electron microscope. The biofilm sensing acituvity was optimized using a Response Surface Method on a statistical software MINITAB with a combination of bacterial concentration variables $\left(10^{6}-10^{10}\right) \mathrm{CFU} / \mathrm{ml}, \mathrm{pH}(4-7)$, and temperature $\left(20-40^{\circ} \mathrm{C}\right)$.

\subsection{Electrochemical Measurement}

Electrochemical measurement was measured by cyclic voltammetry method using eDAQ potentiostat (Ecorder 410). The measurement parameters were done as follows: Mode Cyclic, Initial -900 mV, Final -900mV, Rate 200 mV/s, Step W 20 ms, Upper E 1,200 $m V$, Lower $-900 \mathrm{mV}$. Measurements were carried out with $1 \%$ ethanol solution in $50 \mathrm{~mm}$ phosphate buffer pH 7 as an analyte or substrate, whereas phosphate buffer was used as a blank.

\subsection{Validation Methods of Biosensor}

The validation was carried on analytical, kinetic, stability (Wahab 2006) and selectivity (Karthikeyan et al. 2012) parameters. The analytical parameters were linearity, limit of detection, limit of quantification, sensitivity, and precision. The Linearity was determined from the calibration curve of the concentration series of $0.6,1.0,1.4,1.8,2.2$, 2.6 , and $3.0 \%$ in a $50 \mathrm{~mm}$ phosphate buffer solution of $\mathrm{pH}$ 7. The sensitivity was determined based on linear regression equation of the standard curve. The limit of detection and quantification were calculated according to the linear regression equation of standard curve obtained from 6 replications of the measurements. The precision method was expressed as the percentage of relative raw deviation (\% SBR). The kinetic parameters of alcohol oxidase such as $\mathrm{K}_{\mathrm{M}}$ and $\mathrm{V}_{\max }$ values were determined using the derivative of the Michaelis-Menten equation namely Lineweaver-Burk. The stability was determined from the measurement of 1 biosensor electrode with a certain time interval and expressed in percent. Biosensor selectivity was determined by mixed method. A solution of $1 \%$ ethanol was measured its potential, then a potential measurement of a mixed solution containing $1 \%$ ethanol solution with an interfering solution such as methanol, citric acid, and sodium chloride.

\section{Results}

\subsection{Acetobacter aceti's Biofilm Preparation}

The cultured $A$. aceti had a milky white colony and short rod-shaped cells of Gram negative non spore forming bacteria (Figure 1). It is in line with the Bergey description of Acetobacter aceti.

The $A$. aceti formed biofilm readily on the SPCE as shown in Figure 2.

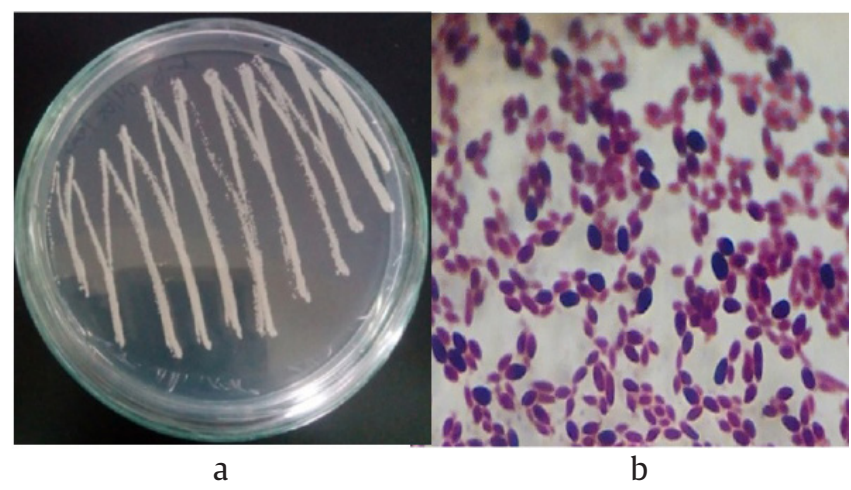

Figure 1. A. aceti cells (a) pure culture of A. aceti, (b) morphology 


\subsection{Electrochemical Measurement}

Mechanism of detecting ethanol on SPCE biofilm A. aceti surface can be shown in Figure 3. The result of ethanol oxidation current measurements with SPCE biofilm was $122,429 \mu \mathrm{A}$ (Figure 4).

\subsection{Validation Methods of Biosensor}

The response surface analysis revealed that the temperature significantly affected the activity as measured as electrical current of the constructed biosensor (Table 1). Relationship between two variables that affect the magnitude of the current can be seen in Figure 4. The constructed biosensor had its optimum condition at bacterial concentration of $1.33 \times 10^{10} \mathrm{cells} / \mathrm{ml}$, measurement temperature of $27^{\circ} \mathrm{C}$ and $\mathrm{pH}$ buffer 7 (Figure 5).

The biosensor's analytical parameters were evaluated based on linearity, sensitivity, limit detection, quantization limit, and precision parameters. The results showed that the ethanol concentration was directly proportional to the intensity of the oxidation peak current (Figure 6).

In term of selectivity, the three interfering compounds with concentrations of $0.5,1.0,1.5$ did not interfere with the performance of electrode measurements against ethanol substrates (Table 2).

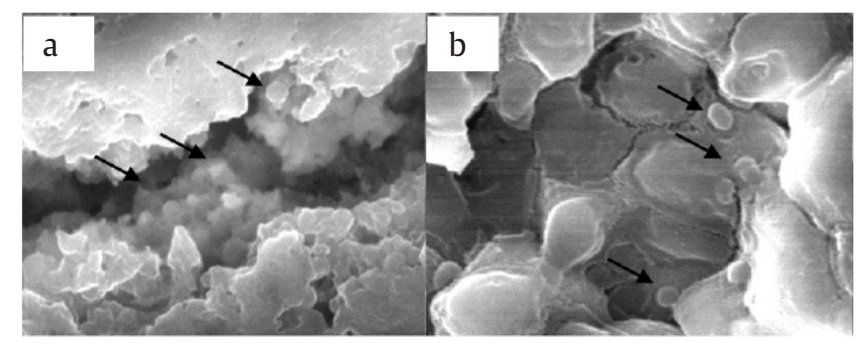

Figure 2. The scanning electron microscope images of Acetobacter aceti biofilm on screen printed carbon electrode. (a) before measurement and stored for 17 days, (b) after repeated measurements and stored for 17 days, observed at 10,000 magnification

\section{Discussion}

\subsection{Acetobacter aceti's Biofilm Preparation}

Acetobacter aceti's biofilm preparation have been constructed. The $A$. aceti formed biofilm readily on the SPCE (Figure 2) as on the other reported surface (Karthikeyan et al. 2012; France 2016). The more the number of $A$. aceti cells given then the more the biofilms formed (France 2016). Initially clustered visible cells were observed that then covered by the biofilm matrix. The matrix protect and maintain the embedded living bacterial cells for a long period of time. Bacteria that have formed biofilms will be more resistant to antimicrobials than planktonic or non-biofilm bacteria (Pantanella et al. 2013).

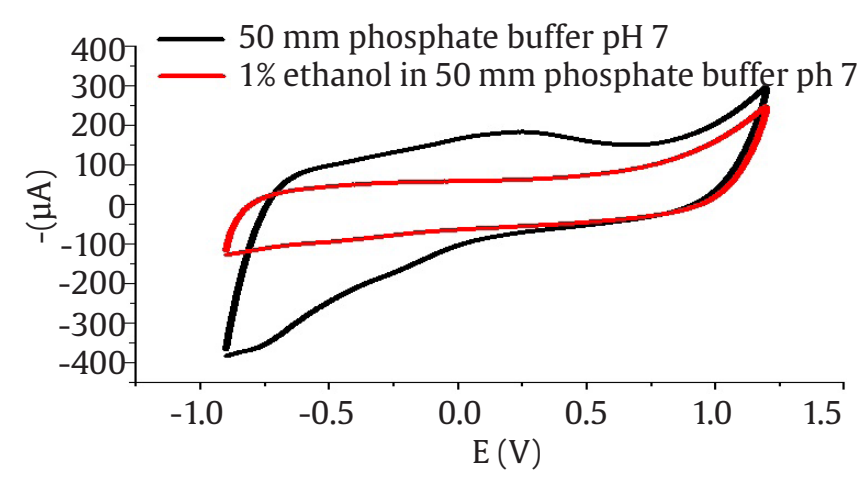

Figure 4. Cyclic voltammogram of ethanol $1 \%$ in $50 \mathrm{~mm}$ phosphate buffer $\mathrm{pH} 7$

Table 1. Analysis result of the effect of variables towards current

\begin{tabular}{lrc}
\hline Factor & Coefficient & p value \\
\hline Constants & -971.833 & 0.001 \\
pH buffer & 123.162 & 0.084 \\
Bacterial concentration & -0.594 & 0.991 \\
Temperature measurement & 50.144 & 0.000 \\
\hline
\end{tabular}

$\mathrm{R}-\mathrm{Sq}=93.29 \% ; \mathrm{R}-\mathrm{Sq}$ (pred) = 51.23\%; R-Sq(adj) = 87.26\%

Figure 3. Mechanism of detecting ethanol on SPCE biofilm A. aceti surface 


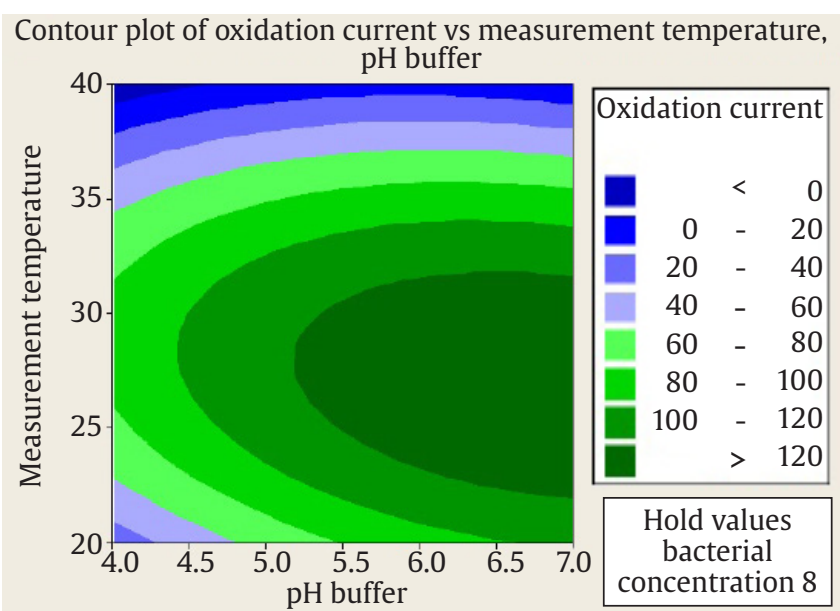

a
Contour plot of oxidation current vs measurement temperature, bacterial concentration

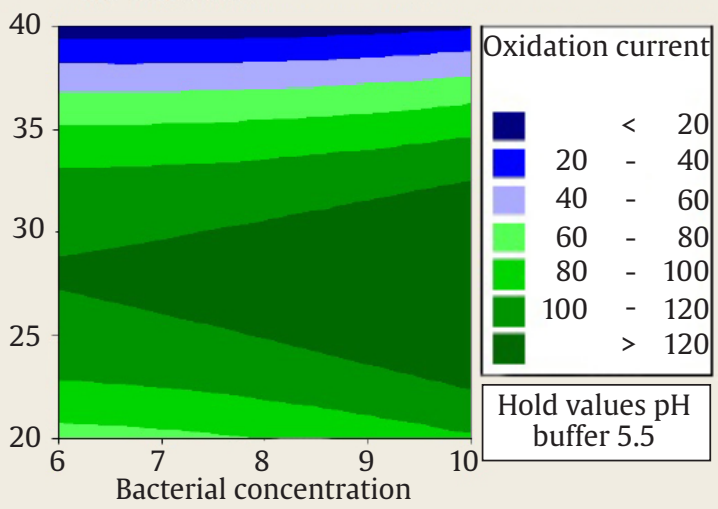

b

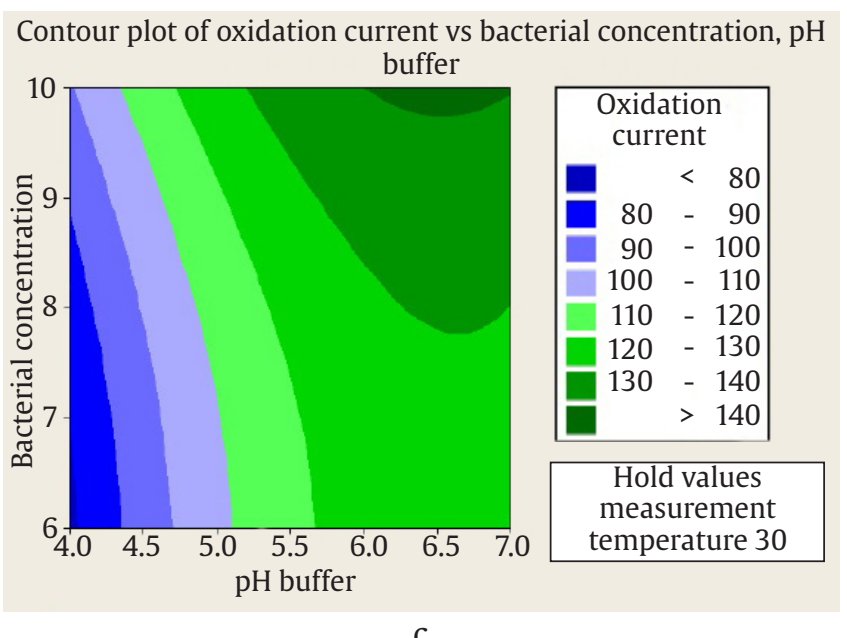

Figure 5. (a) Influence of measurement temperature and $\mathrm{pH}$ buffer to current, (b) influence of measurement temperature and bacterial concentrations to current, (c) influence of bacterial concentration and $\mathrm{pH}$ buffer to current

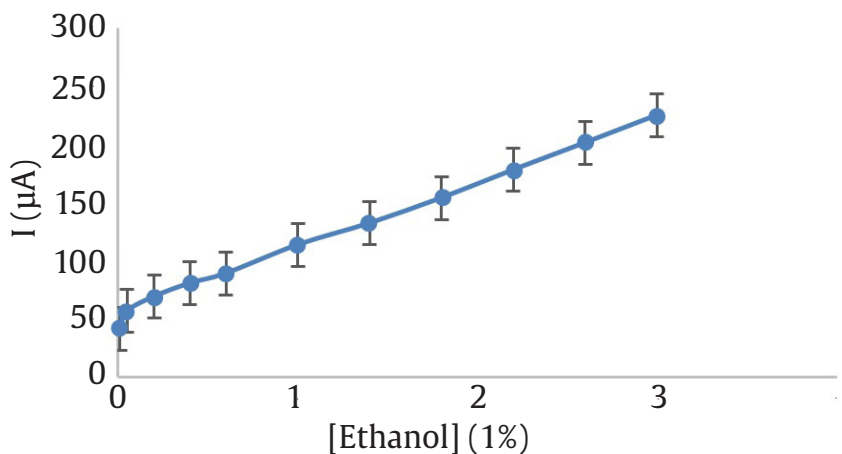

Figure 6. Linear regression curve, relationship [ethanol] with the oxidation peak current

\subsection{Electrochemical Measurement}

The ethanol as a substrate was detected and measured by the alcohol oxidase enzyme as the bioreceptor. Its catalytic reaction of oxidation reaction
Table 2. Coefficient of selectivity of interfering on ethanol substrate

\begin{tabular}{lcc}
\hline Interfering compound & [Compound] (\%) & $\mathrm{K}_{\mathrm{iij}}$ \\
\hline Methanol & 1.5 & -29.889 \\
Methanol & 1 & -34.333 \\
Methanol & 0.5 & -39.889 \\
$\mathrm{NaCl}$ & 1.5 & -3.5 \\
$\mathrm{NaCl}$ & 1 & -9.75 \\
$\mathrm{NaCl}$ & 0.5 & -13.5 \\
Citric Acid & 1.5 & -28.5 \\
Citric Acid & 1 & -38.5 \\
Citric Acid & 0.5 & -53.5 \\
\hline
\end{tabular}

of ethanol to acetaldehyde with the aid of available oxygen as an oxidizer which will be reduced to hydrogen peroxide. This reverse redox reaction between oxygen and hydrogen peroxide will produce transferred electrons causing a current to be sent by electrode to transducer in the form of a signal. This signal by the 
transducer is converted into electromagnetic waves which can be read and recorded by the recorder as the peak of ethanol oxidation current (Figure 3 ). The result of ethanol oxidation current measurements with SPCE biofilm was $122,429 \mu$ A (Figure 4). Previous studies had lower oxidation current peaks, 2,856 $\mu \mathrm{A}$ (Iswantini et al. 2016), $2.34 \mu \mathrm{A}$ (Iswantini et al. 2017), and $750 \mathrm{nA}$ (Rama et al. 2012). In fact the optimum pH buffer for alcohol oxidase by electrochemical method occurred at pH 6 (Rama et al. 2012), pH 7.2 , pH 7 (Carelli et al. 2006; Türkarslana et al. 2010).

\subsection{Validation Methods of Biosensor}

The biosensor's analytical parameters were evaluated based on linearity, sensitivity, limit detection, quantization limit, and precision parameters. The results showed that the ethanol concentration was directly proportional to the intensity of the oxidation peak current (Figure 6). The linear relationship between the concentration of ethanol and the intensity of the anodic peak current follows the equation $y=57.29 x+53.03$ with $\mathrm{R} 2=0.993$. Linearity is the ability of the analytical method to provide a proportional response to the concentration of the analyte in the sample. The sensitivity value obtained in this study was $57.29 \mu \mathrm{A}$ (\%)-(Niculescu et al. 2002). The higher the sensitivity value, the more sensitive the method used. The limit of detection and quantification of the constructed biosensor were 0.003 and $0.009 \%$ respectively. These low limit values indicate that the sensitivity of the method used is very good. The obtained LD and LK values have met the ethanol concentration limit in the process of making food and beverages that was $<1 \%$. However, the obtained limit of detection was greater than those of the value of the previous research that was $0.02 \mathrm{~mm}$ (Rama et al. 2012), 0.035\% (Shkotova et al. 2005), $2.3 \mu \mathrm{m}$ (Carelli et al. 2006). Interestingly, the precision for the measurement accuracy expressed as the percent value of relative standard deviation of $1.95 \%$ indicated a good accuracy.

The kinetics analysis revealed that the biosensor had KM value of $3.5 \mathrm{~mm}$ and Vmax of $125 \mu \mathrm{A}$ (Figure 7 ). The KM value indicates the strength of an enzyme in binding to the substrate. The greater the KM value, the weaker the enzyme binds to the substrate and vice versa. The KM value of this biosensor was higher than that of the pure enzyme of Hansenula yeast which amounted to $2.4 \pm 0.7 \mathrm{~mm}$ (Rama et al. 2012). However, this KM value was lower than that of the pure enzyme of Pichia pastoris yeast which amounted to $7.8 \mathrm{~m}$ (Türkarslana et al. 2010). It seem that the difference in KM values was due to differences in the source of the enzyme and the applied measurement methods.

The main problem of alcohol oxidase based biosensors is their limited stability (Kuswandi et al. 2014). The results showed that biofilm $A$. aceti on the SPCE surface remained stable after the $55^{\text {th }}$ day of measurement with residual activity of $100.34 \%$, however no measured data after that time (Figure 8). This constructed alcohol biosensor had a higher stability than that of the pure enzyme -based ethanol biosensor of $A$. aceti using a 3-day EPK with residual activity of 22.34\% (Iswantini et al. 2016) a pure enzyme -based ethanol biosensor from Pichia Pastoris yeast of the 28 days with remaining activity of $20 \%$ (Türkarslana et al. 2010) and 5 days (Shkotova et al. 2005). The ethanol biosensor of the pure enzyme from Hansenula yeast immobilized on SPCE reached 2 months (Rama et al. 2012). In term of selectivity, the three interfering compounds with concentrations of $0.5,1.0,1.5$ did not interfere with the performance of electrode measurements against ethanol substrates (Table 2), as

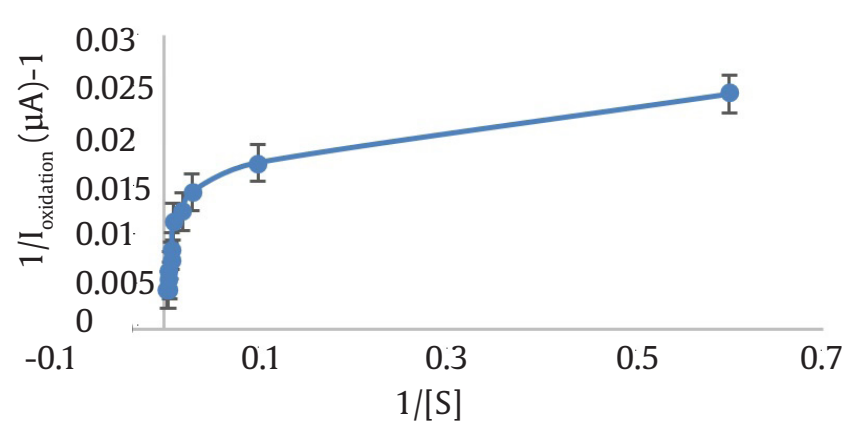

Figure 7. Lineweaver-burk curve relationship between 1/ $[S]$ and $1 / I_{\text {oxidation }}$

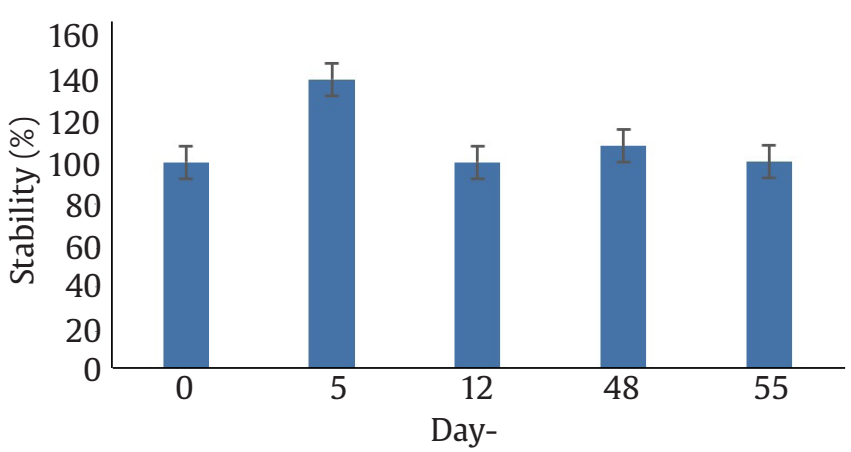

Figure 8. Stability of ethanol biosensors with SPCE biofilm A. aceti 
indicated by the selectivity coefficient was lower than 1 (Wahab 2006). The selectivity coefficient is a factor that reduce the selectivity of electrode (Wahab 2006). Interference from other ions may affect potential readings resulting in cross sensitivity and may decrease the activity of the main ion.

\section{Conclusion}

The constructed alcohol biosensor of $A$. aceti biofilm on the SPCE had good and better activity and stability than those of the reported biosensor using a carbon paste electrode. The biofilm on the SPCE provide a longer viable bacterial cell producing active alcohol oxidase as bioreceptor and catalysator in the alcohol detection and measurement.

\section{References}

Abed SE et al. 2012. Scanning electron microscopy (sem) and environmental sem: suitable tools for study of adhesion stage and biofilm formation. INTECH Open Access Publisher 35:717-730.

Alferov VA et al. 2011. An alcohol oxidase-based electrochemical sensor for rapid determination of lower alcohol.Journal of Analytical Chemistry 66:1205-1211.

Alpat S, Telefoncu A. 2010. Development of an alcohol dehydrogenase biosensor for ethanol determination with toluidine blue o covalently attached to a cellulose acetate modified electrode. Sensors 10:748-764.

Apers S et al. 2003. Quality control of liquid herbal drug preparations: ethanol content and test on methanol and 2-propanol. Journal of Pharmaceutical and Biomedical Analysis 33:529-537.

Azevedo AM et al. 2005. Ethanol based on alcohol oxidase. Biosensors and Bioelectronics 21:235-247.

Bilgi M, Ayranci E. 2016. Biosensor application of screenprinted carbon electrodes modified with nanomaterials and a conducting polymer: ethanol biosensors based on alcohol dehydrogenase. Sensors and Actuators B: Chemical 27:849-855.

Carelli D et al. 2006. An interference-free first generation alcohol biosensor based on a gold electrode modified by an overoxidised non-conducting polypyrrole film. Analytica Chimica Acta 565:27-35.

Chinnadayyala SR et al. 2015. Alcohol oxidase protein mediated in-situ synthesized and stabilized gold nanoparticles for developing amperometric alcohol biosensor. Biosensors and Bioelectronics 69:155-161.

Cinti S et al. 2017. A paper-based nanomodified electrochemical biosensor for ethanol detection in beers. Analytica Chimica Acta 960:123-130.
France DC. 2016. Anticorrosive influence of Acetobacter aceti biofilms on carbon steel.Journal of Materials Engineering and Performance 25:3580-3589.

Iswantini D et al. 2016. Electrochemical Biosensor Using Acetobacter Enzyme for Detecting Alcohol. Preprints 2016. DOI:10.20944/preprints201610.0107.v1

Iswantini D et al. 2017. Alcohol dehydrogenase of Bacillus strain for measuring alcohol electrochemically. IOP Conf Ser Earth Environ Science 58: 012010. DOI:10.1088/1755$1315 / 58 / 1 / 012010$

Karthikeyan R et al. 2012. Bio-electrocatalysis of Acetobacter aceti through direct electron transfer using a template deposited nickel anode. Catalysis Science and Technology 2:1234-1241.

Kurbanoglu S, Toppare L. 2014. Ethanol biosensor based on immobilization of alcohol oxidase in a conducting polymer matrix via crosslinking with glutaraldehyde. Revue Roumaine de Chimie 60:453-460.

Kuswandi B et al. 2014. A simple visual ethanol biosensor based on alcohol oxidase immobilized onto polyaniline film for halal verification of fermented beverage samples. Sensors 14:2135-2149.

Mendes LS et al. 2003. Determination of ethanol in fuel ethanol and beverages by Fourier transform (FT)-near infrared and FT-Raman spectrometries. Analytica Chimica Acta 493:219-231.

Merritt JH et al. 2011. Growing and analyzing static biofilms. Current Protocols in Microbiology. Hoboken: John Wiley and Sons Inc 22:1B.1.1-1B.1.18. DOI:10.1002/9780471729259.mc01b01s00

Niculescu M et al. 2002. Quinohemoprotein alcohol dehydrogenase-based reagent-less amperometric biosensor for ethanol monitoring during wine fermentation. Anal Chim Acta 463:39-51.

Pantanella F et al. 2013. Analytical techniques to study microbial biofilm on abiotic surfaces: pros and cons of the main techniques currently in use. Ann Ig 25:31-42.

Rama CE et al. 2012. Comparative study of different alcohol sensors based on screen-printed carbon electrodes. Analytica Chimica Acta 728:69-76.

Rotariu L et al. 2004. New potentiometric microbial biosensor for ethanol determination in alcoholic beverages. Analytica Chimica Acta 513:119-123.

Santos AS et al. 2003. Higly stable amperometry biosensor for ethanol based on Meldola's blue adsorbed on silica gel modified with niobium oxide. Journal of Electroanalytical Chemistry 547:135-142.

Shkotova VL et al. 2005. Amperometric biosensor for ethanol detection based on alcohol oxidase immobilised within electrochemically deposited resydrol film. Materials Science and Engineering: C 26:411-414.

Su L et al. 2010. Microbial biosensors: a review. Biosensors and Bioelectronics 26:1788-1799.

Türkarslana O et al. 2010. Amperometric alcohol biosensors based on conducting polymers: polypyrrole, poly(3,4-ethylenedioxythiophene) and poly(3,4ethylenedioxypyrrole). Synthetic Metals 160:808-813. 
Wahab WA 2006. The effect of PVC-based membrane composition and $\mathrm{Zn}(\mathrm{II}), \mathrm{Cd}(\mathrm{II})$ and $\mathrm{Pb}(\mathrm{II})$ interfering ions to $\mathrm{Hg}(\mathrm{II})$ ion selective electrode (ISE) performance by using DBA $18 C 6$ ionophore. Ind J Chem 6:27-31.

Wen G et al. 2013. Detection of ethanol in food: a new biosensor based on bacteria. Journal of Food Engineering 118:56-61.

Xia F et al. 2010. Simultaneous determination of copper, lead, and cadmium at hexagonal mesoporous silica immobilized quercetin modified carbon paste electrode. Journal of Automated Methods and Management in Chemistry 10:1-6.
Yarita T et al. 2002. Determination of ethanol in alcoholic beverages by high-high performance liquid chromatography-flame ionization detection using pure water as mobile phase. Journal of Chromatography $A$ 976:387-391.

Zanon JP et al. 2007. Colorimetric assay of ethanol using alcohol dehydrogenase from dry baker's yeas. Enzyme and Microbial Technology 40:466-470. 